\title{
Predicting and mapping malaria under climate change scenarios: the potential redistribution of malaria vectors in Africa
}

\author{
Henri EZ Tonnang*, Richard YM Kangalawe and Pius Z Yanda
}

\begin{abstract}
Background: Malaria is rampant in Africa and causes untold mortality and morbidity. Vector-borne diseases are climate sensitive and this has raised considerable concern over the implications of climate change on future disease risk. The problem of malaria vectors (Anopheles mosquitoes) shifting from their traditional locations to invade new zones is an important concern. The vision of this study was to exploit the sets of information previously generated by entomologists, e.g. on geographical range of vectors and malaria distribution, to build models that will enable prediction and mapping the potential redistribution of Anopheles mosquitoes in Africa.

Methods: The development of the modelling tool was carried out through calibration of CLIMEX parameters. The model helped estimate the potential geographical distribution and seasonal abundance of the species in relation to climatic factors. These included temperature, rainfall and relative humidity, which characterized the living environment for Anopheles mosquitoes. The same parameters were used in determining the ecoclimatic index (EI). The El values were exported to a GIS package for special analysis and proper mapping of the potential future distribution of Anopheles gambiae and Anophles arabiensis within the African continent under three climate change scenarios.

Results: These results have shown that shifts in these species boundaries southward and eastward of Africa may occur rather than jumps into quite different climatic environments. In the absence of adequate control, these predictions are crucial in understanding the possible future geographical range of the vectors and the disease, which could facilitate planning for various adaptation options.

Conclusion: Thus, the outputs from this study will be helpful at various levels of decision making, for example, in setting up of an early warning and sustainable strategies for climate change and climate change adaptation for malaria vectors control programmes in Africa.
\end{abstract}

\section{Background}

The Anopheles mosquitoes are the worldwide known vectors of malaria. In Africa, three Anopheles species: Anopheles gambiae, Anopheles arabiensis and Anopheles funestus are considered to be the major vectors most responsible for malaria transmission. The first two species belong to a group called A. gambiae complex, which is considered to be the most efficient malaria vector in the world [1]. Actual and future geographical distribution of these mosquito species is vital for malaria control strategic planning.

\footnotetext{
* Correspondence: htonnang@gmail.com

1 Institute of Resource Assessment, University of Dar Es Salaam, PO Box 35097, Dar es Salaam, Tanzania

Full list of author information is available at the end of the article
}

Pioneer work on malaria vector distribution [2,3] only reflected entomologists' opinion rather than the ecological niche of Anopheles. Lindsay et al [4] attempted the prediction for Anopheles species occurrence in Africa using climatic and distributional data. Coetzee et al [5] mapped African malaria vector species based on actual collections. The genetic algorithm for rule-set prediction (GARP) model was used to predict the geographical and ecological distribution of three species of the A. gambiae complex (A. gambiae, A. arabiensis, and Anopheles quadriannulatus). The approach was based on relating ecological niches of species point occurrence data to electronic maps of relevant ecological dimensions in order to 
produce rules that describe the potential distribution of the species [1].

Early hypothesis about climate change and vectorborne diseases in general proposed that increased temperature and precipitation could facilitate the emergence and persistence of Anopheles mosquitoes [6]. Furthermore, vector-borne diseases, such as malaria, would respond most promptly to localized warming events. Expected mosquitoes ranges increase with increased temperature, towards temperate regions, has been suggested [7]. A recent study by Lafferty [8] has added into the long-standing debate on how global warming will affect the prevalence and distribution of human vectorborne diseases. This author's analysis suggested that Anopheles distribution range shifts are more likely to occur than range expansions. It is then clear that one of the major threats for the current functioning of the world is the uncertainty about the effects of global climate change. Working knowledge of where malaria vectors specially occur and will potentially occur in the future under climate change scenarios is very essential for the malaria control programme managers and policy makers. Entomologists and malariologists throughout the African continent have collected distributional and biological data. This study aims to make use of these records to increase the understanding and produce potential future distributional maps for two members of the A. gambiae complex; A. gambiae and A. arabiensis under different climate change scenarios. The CLIMEX model, which is a platform, designed to infer species responses to climate from observations on their geographical distribution and seasonal phenology was used for the effect $[9,10]$.

\section{Methods}

\section{Data sets}

The distributional records for malaria vectors used in this study came from the ARMA/MARA website [11], recent scientific publications and reports [12-14]. The meteorological data included: the average minimum daily temperature, the average maximum daily temperature, the average monthly rainfall, and the average daily relative humidity at 9 am and at $3 \mathrm{pm}$. This database was made with selected locations worldwide as well as interpolated climatic grids $\left(5^{\circ} \times 5^{\circ}\right)$ provided by the global change community through the Climatic Research Unit (CRU) in Norwich UK. The stations coverage is denser over the more populated parts of the world. The observation began with small number of stations during the 1850s, but increases to over 3,000 stations during the 1951-90 period.

\section{Assumptions}

The African climate is diverse and varied. It is diverse because it ranges from humid equatorial regimes, through seasonally arid tropical regimes, to sub-tropical Mediterranean type. By this diversity, it demonstrates different degrees of spatial variability, particularly with regard to rainfall [15]. The temperatures vary greatly throughout the continent and each country has unique climatic conditions [15]. The altitude sometimes also moderates the climate. Based on these considerations, the African continent was divided into subsequent climatic zones:

- The band of latitudes centred on the equator was considered as the equatorial zone and the winter and summer seasons were defined with reference to the equatorial zone and the day of the year.

- To the north of the equatorial zone, summer was defined as the days from March 2 - September 30, with winter being the rest of the year. Reinforcing the same argument, south of the equatorial zone, the situation was the reverse.

\section{Climate change scenarios}

Two major reasons guided the choice for the climate change scenarios; the first was linked to African climate as mentioned earlier and the second, the response of Anopheles mosquitoes to temperature and rainfall. The temperature, rainfall and humidity are important determinant factors for the Anopheles distribution. A little increase in temperature leads to an increase in the mosquito's development and the adult frequency of blood feeding [16]. The Anopheles breeding and survival are determined and characterized by rainfall and humidity. In relation to these criteria the following scenarios were chosen:

a) Scenario 1: A rise of $2^{\circ} \mathrm{C}$ Africa wide temperature, and $10 \%$ increase of summer rainfall and $10 \%$ decrease in winter rainfall.

b) Scenario 2: $\mathrm{A} 0.1^{\circ} \mathrm{C}$ rise in summer and winter maximum and minimum temperatures per degree of latitude, and a $10 \%$ increase in rainfall in summer, and $10 \%$ decrease in winter.

c) Scenario 3: A rise of $4{ }^{\circ} \mathrm{C}$ Africa wide temperature, and $20 \%$ increase of summer rainfall and $20 \%$ decrease in winter rainfall.

\section{Model}

Many theories accounting for the abundance, distribution, change and variation of species population have been proposed. They can broadly be divided in two classes; the first class regrouped those that view climate either directly or indirectly through its interactions with species-specific characters, as the major determining factor [17], and the second class gathered those that view multi-species interactions such as competition and predation as being the paramount [18] component for species distribution. The conceptual framework of the model 
used in this study was based on the first school of thought that stipulated that climate most likely has a major influence on the species abundance.

The platform applied is called CLIMEX. The model theory is generally based on the species estimated responses to temperature and moisture. The CLIMEX model estimates are founded on the assumption that if you know where a species lives, you can infer what climatic conditions it can tolerate. In other words, CLIMEX attempts to mimic the mechanisms that limit species geographical distributions and determine their seasonal phenology and to a lesser extent their relative abundance $[9,10]$. It derives weekly and annual indices that describe the responses of a nominated species to temperature and moisture. Furthermore, this model assumes that a species at a given location experience two seasons during a year, one with population growth and the other with population decline. These are referred to as growth or survival and stress seasons, respectively. The overall climatic suitability of a nominated location for a given organism is provided by an Ecoclimatic Index (EI), which combines the annual potential for population growth $\left(\mathrm{GI}_{\mathrm{A}}\right)$, with the annual stresses that limit survival during the unfavourable season (SI) and with the limiting interacting factor between stresses (SX) [19]. These indices are calculated as follows:

$$
\begin{aligned}
& \mathrm{GI}_{\mathrm{A}}=\sum_{i=1}^{52} \frac{T I^{*} M I_{W}}{52} \\
& \mathrm{SI}=\left(1-\frac{C S}{100}\right)\left(1-\frac{D S}{100}\right)\left(1-\frac{H S}{100}\right)\left(1-\frac{W S}{100}\right) \\
& \mathrm{SX}=\left(1-\frac{C D X}{100}\right)\left(1-\frac{C W X}{100}\right)\left(1-\frac{H D X}{100}\right)\left(1-\frac{H W X}{100}\right)
\end{aligned}
$$$$
\mathrm{EI}=\mathrm{GI}_{\mathrm{A}} * \mathrm{SI} * \mathrm{SX},
$$

Where: $\mathrm{TI}_{\mathrm{W}}$ and $\mathrm{MI}_{\mathrm{w}}$ are the weekly temperature and moisture respectively, 52 is the number of weeks in a year. CS, DS, HS and WS are the annual cold, dry, heat and wet stress indices respectively. CDX, CWX, HDX and HWX are the annual cold-dry, cold-wet, hot-dry and hot-wet stress interactions indices respectively.
The locations with positive values for EI are suitable for a species, and the larger the value of EI, the more suitable the location. As few climates are 100\% suitable throughout the year, the value of EI will rarely reach its potential, thereby limiting the maximum value of EI [19].

\section{Model building, prediction test and special analysis}

In building the model, the usually observed geographical distribution data from African countries belonging to the sub-Saharan region was mapped in accordance with each chosen Anopheles species population growth rate, the developmental threshold temperature and moisture levels. The CLIMEX model parameters were repeatedly adjusted and the function "Compare location", which describes the potential geographical distribution of a species, as limited by climate was re-run until the estimated potential Anopheles species range best matched the observed or known distribution.

In order to test the model's predictive capability, it was initially intended to use independent data; meaning records that do not have any connection with the information applied, for model parameters estimation. However, this intention encountered difficulties as the two species (A. gambiae and A. arabiensis) under prediction only occur in Africa and in no other location in the world. Soper and Wilson [20] recorded the establishment of one species of the A. gambiae complex in north-eastern part of Brazil around 1930 to 1940 to have been via accidental introduction. Therefore, the opportunity of using South America for the developed model validation became possible and practical. The parameters estimated from the building exercise were then used to run the "Compare location" function in South American region for predicting the Anopheles species potential distribution in northeastern parts of Brazil. This and the building exercises were successively repeated by slightly adjusting parameters until a 'good fit' for the known distribution in Africa and mentioned location in South America, was obtained respectively.

The treatment of climate change was thereafter performed for the African continent. Best-matched parameters were fitted for mapping the Anopheles species under current conditions before the climate change scenarios were successively stated. The "compare location" was once again run and the EI for the A. gambiae and A. arabiensis were evaluated under current and the chosen climate change scenarios respectively. The differences between the values of EI for individual climate change scenario and the current scenario was performed for each Anopheles species. The obtained results were then transferred to Arc-GIS 9.2 package in order to facilitate the organization, manipulation, visualization, and for geospatial analysis. 


\section{Results}

Potential current and future distribution of malaria vectors in Africa

The CLIMEX parameters (Table 1) were inferred from field and laboratory, or were estimated iteratively through manual adjustment until the model predictions matched the observed records well. The values of the EI show that the climate is most favourable for A. arabiensis within the drier savannah areas of the continent (Figure 1a). In the opposite, the most suitable region for A. gambiae is the wet tropical region (Figure 2a). Both figures represent the simulations using parameter values presented in Table 1. These illustrations are generally in agreement with previous conclusions [4,5], which described A. arabiensis and A. gambiae to be favourable in warmer and wetter environments or habitats respectively. Poor model fit in few localities may be due to the quality and insufficiencies of the African climate data used. Several countries were represented by only one or two stations and thus it can be said that the data used for such areas are coarse and may contain uncertainties that vary over small spatial scale.

The obtained maps (Figures 1b-c) and (Figures 2b-c) are for the difference between the values of EI of each climate change scenario and the current climate for A. arabiensis and A. gambiae respectively. Figure $1 \mathrm{~b}$ describes the values of EI for climate change Scenario 1 minus the values of EI for $A$. arabiensis under current climate. Usually, the EI values are ranged between 0 and 100. An EI value close to 0 indicates that the location is not suitable for long-term survival of the species where as an EI value of 100 is equated to an ideal condition. However, some of the legends have shown negative EI values, this is because 'smaller' and positive EI values were subtracted from 'bigger' values. The goal of this exercise was to identify regions with either reduction or addition/surplus in suitability for the vectors, and evaluate their percentage.

All chosen climate change scenarios demonstrated that "under business as usual condition" the western and some region of central part of Africa might, with time, loose their habitat suitability for both studied Anopheles species. Under climate change scenario 1, 2 and 3 the West African region will become less suitable for both species ranges, whereas the malaria vectors may be shifting towards the eastern and southern regions of the continent. In contrast, the southern and eastern part of the continent might become more favourable for the development of the African malaria vectors.

In the legends, the rectangles $(0-0)$ represent unchanged zones in terms of species suitability. In all circumstances, these regions are few, proving that changes in African malaria vectors distribution under rising temperature and rainfall variability is real. The EI values vary from $(0$ - 40) and from $(0$ - 100) and (-70 - 70) for A. arabiensis and $A$. gambiae respectively. This discrepancy is due to the changes on the dynamics of climate characteristics in savannah areas compared to wet regions. The savannah is characterized by a distinct dry season, which is generally in the winter and the rainy season in the summer months. During the dry seasons some rivers recede into pools and streams dry up. These pools may serve as breeding sites for malaria vectors.

It is convenient that predictive models for continental species distribution should be tested using independent data sets from the same species ranges in another continent different from the one used for model development. This is because a species requires almost identical factors everywhere on the planet Earth in order to survive. The methodology mentioned a retrospective event of the 1930s, where a member of the A. gambiae complex was imported to Brazil. During that period, the A. gambiae was yet to be recognized as a complex of multiple species, and the real identity of the member of the complex that was responsible for malaria transmission in the area remained unidentified, and speculations have been made that the species that invaded the area was either A. gambiae or A. arabiensis. In validating the model, it was suggested and established that the A. gambiae species was likely responsible for the deadly malaria outbreak in southern eastern Brazil around the 1930s (Figure 3).

\section{Discussion}

The modelling approach enabled results to be directly exported to Arc-GIS 9.2 for standardised spatial analysis. The representation of the results became sensible showing species ranges rather than simple point estimates which usually incorporates much of the uncertainty surrounding the input parameters, and allow unclear conclusions to be drawn. Another advantage of the applied methodology is that it does allow the user to obtain useful predictions with minimum information. This was demonstrated through the fact that the database on actual distribution of malaria vectors in Africa is filled with blank areas where no species identification has been published. Nevertheless, satisfactory outputs were obtained.

The results of this study can be compared with other analyses: Lindsay et al [4], Coetzee et al [5] and Levine et al [1]. The first authors used climatic and distributional data to predict the African malaria vectors occurrence, but this resulted in maps with limitations. The A. arabiensis was projected to occur in South Africa, within an arid region with no rivers. The discrepancy in such results is obvious, as the mosquitoes cannot survive in areas without possibility for breeding sites. The second study by Coetzee et al [5] only mapped climatic factors comprising the actual distribution of malaria vectors. No attempt was made in predicting future distribution of the species. The third authors [1] used ecological niche modelling to predict the potential distribution of A. gambiae 


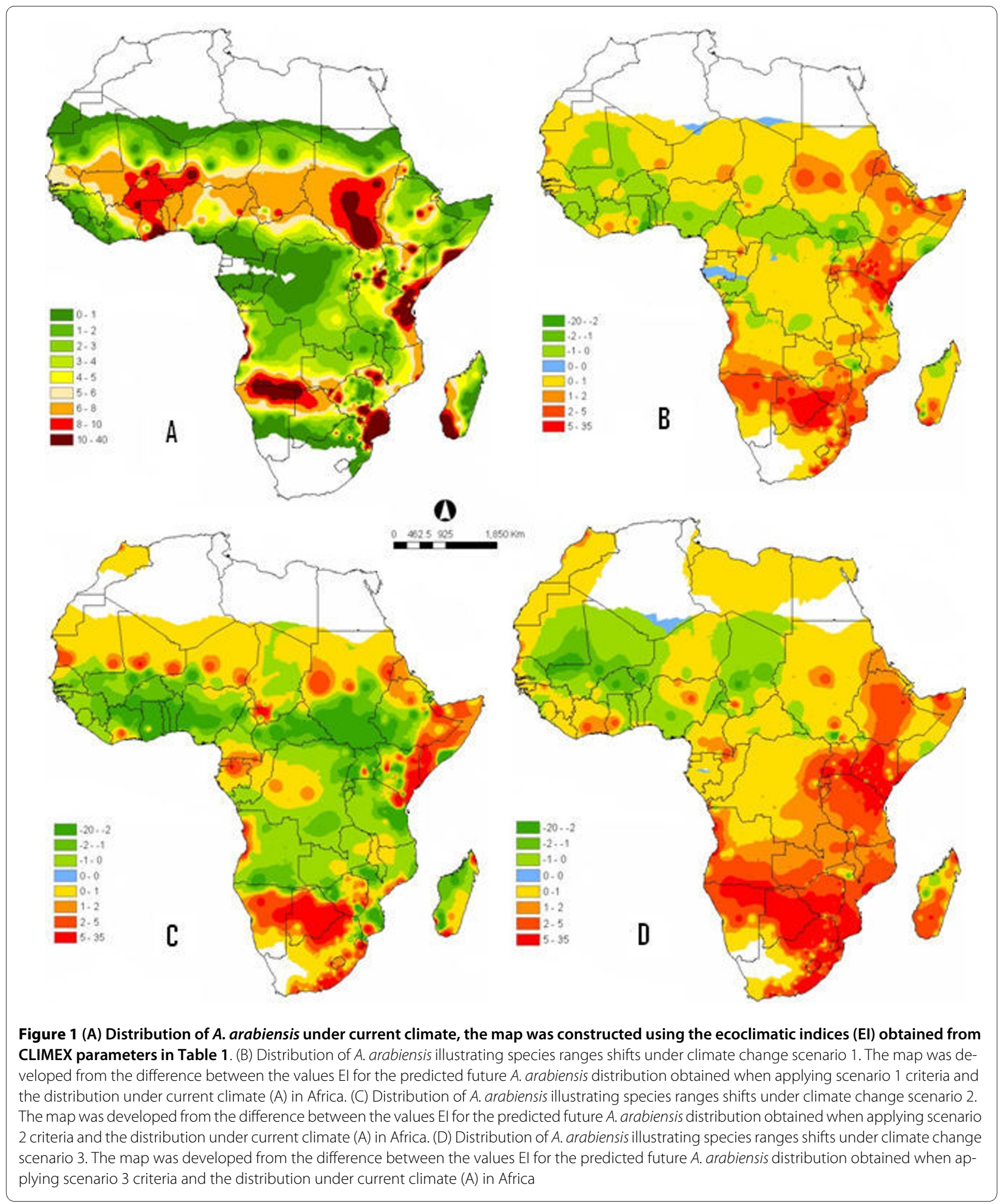

complex. However, their results projected that A. arabiensis will be redistributed across most of central Africa, which is generally humid. This is unlikely to be realistic because the $A$. arabiensis mostly inhabits semiarid environments.
These results generally agree with current observed maps of malaria vectors. When applying different climate change scenario analyses, they displayed different possible changes in suitability within the continent. These analyses have proven that changes in ranges for both 


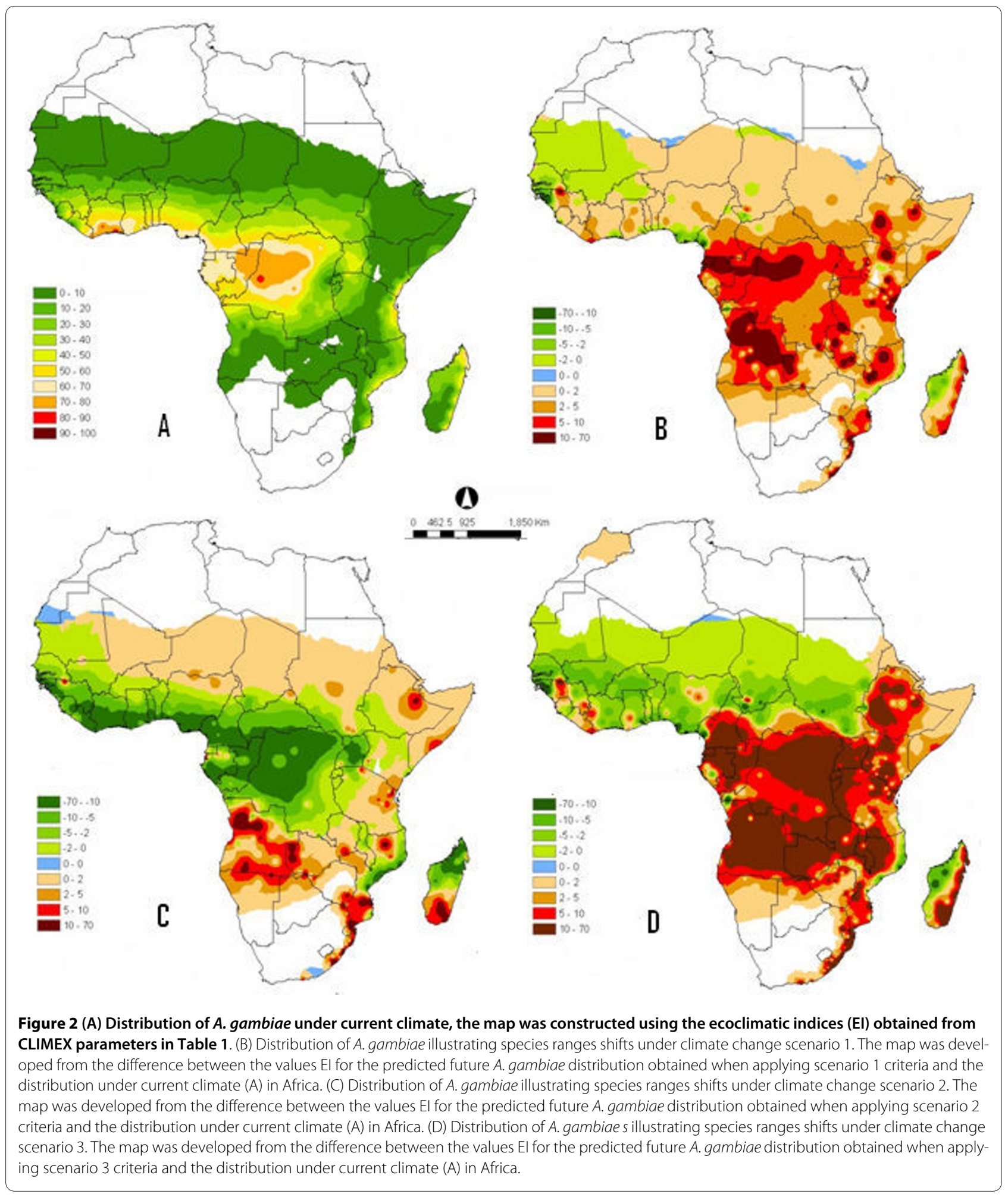

Anopheles species under climate change are likely to be incremental and nonlinear. The present results have shown that shifts in these species boundaries southwards and eastwards of Africa may occur rather than jumps into quite different climatic environments. However, some nonlinear responses may appear where independent variables, such as interspecific interactions that are indifferent to changing climate parameters may influence the species. This research output suggests that Anopheles population abundance, in particular $A$. gambiae, towards 
Table 1: CLIMEX parameters values for African malaria vectors belonging to the Anopheles gambiae complex

\section{Values}

\section{Parameter designation}

Moisture parameters (proportion of soil moisture holding capacity)

Lower threshold of soil moisture

(SM0)

Lower limit of optimal range of soil moisture (SM1)

Upper limit of optimal range of soil moisture (SM2)

Upper threshold of soil moisture

(SM3)

\section{Temperature parameters $\left({ }^{\circ} \mathrm{C}\right)$}

Lower threshold of temperature for population growth (DVO)

Lower optimal temperature for population growth (DV1)

Upper optimal temperature for population growth (DV2)

Upper threshold temperature for population growth (DV3)

\section{Dry stress indices}

Soil moisture dry stress (proportion of soil holding capacity) (SMDS)

Rate of accumulation of dry stress (HDS)

\section{A. gambiae}

0.80

\section{Wet stress indices}

Soil moisture wet stress (proportion of

Rate of accumulation of wet stress (HWS)

\section{Heat stress indices}

Threshold of heat stress (TTHS)

Rate of accumulation of heat stress

(TTHS)

\section{Cold stress indices}

Temperature threshold of cold stress

(TTCS) 
Table 1: CLIMEX parameters values for African malaria vectors belonging to the Anopheles gambiae complex (Continued)

\section{Cold-wet stress indices}

Degree-days threshold of cold-wet stress (DTCW)

Moisture threshold of cold-wet stress (MTCW)

Rate of accumulation of cold-wet stress (PCW)
30.000

0.100

0.001 the eastern and southern parts of Africa may increase considerably with the projected climate scenario 1 and 3 than with scenario 2. This means that Africa's temperature rise by $0.1^{\circ} \mathrm{C}$ per degree latitude will provoke less changes on the malaria vectors distribution than an Africa wide temperature increase of $2^{\circ} \mathrm{C}$ to $4^{\circ} \mathrm{C}$.

In the past years, a member of the A. gambiae complex demonstrated its ability of taking advantage of modern means of transport to become established in regions (north-eastern Brazil) outside its normal area of geographical distribution as was illustrated during the model validation. The present research has guided us in suggesting that $A$. gambiae is most likely to be the species responsible for the 1930's malaria outbreak in Brazil.
Another range extension of a member of the A. gambiae complex occurred in about 1942 into Upper Egypt [21]. As in Brazil, its arrival was heralded by severe epidemics of malaria. As already mentioned above, in the course of that event, scientists were still unaware that $A$. gambiae was a complex. In the light of this study, the probable species concerned with the range expansion in Upper Egypt could have been the A. arabiensis. This argument is based on the fact that the northern limits of distribution for $A$. arabiensis in the Nile Valley are normally in the northern part of the Sudan. Seasonal climate fluctuation may easily favour the species invasion in neighbouring regions, and it is also possible that similar unrecorded invasions have

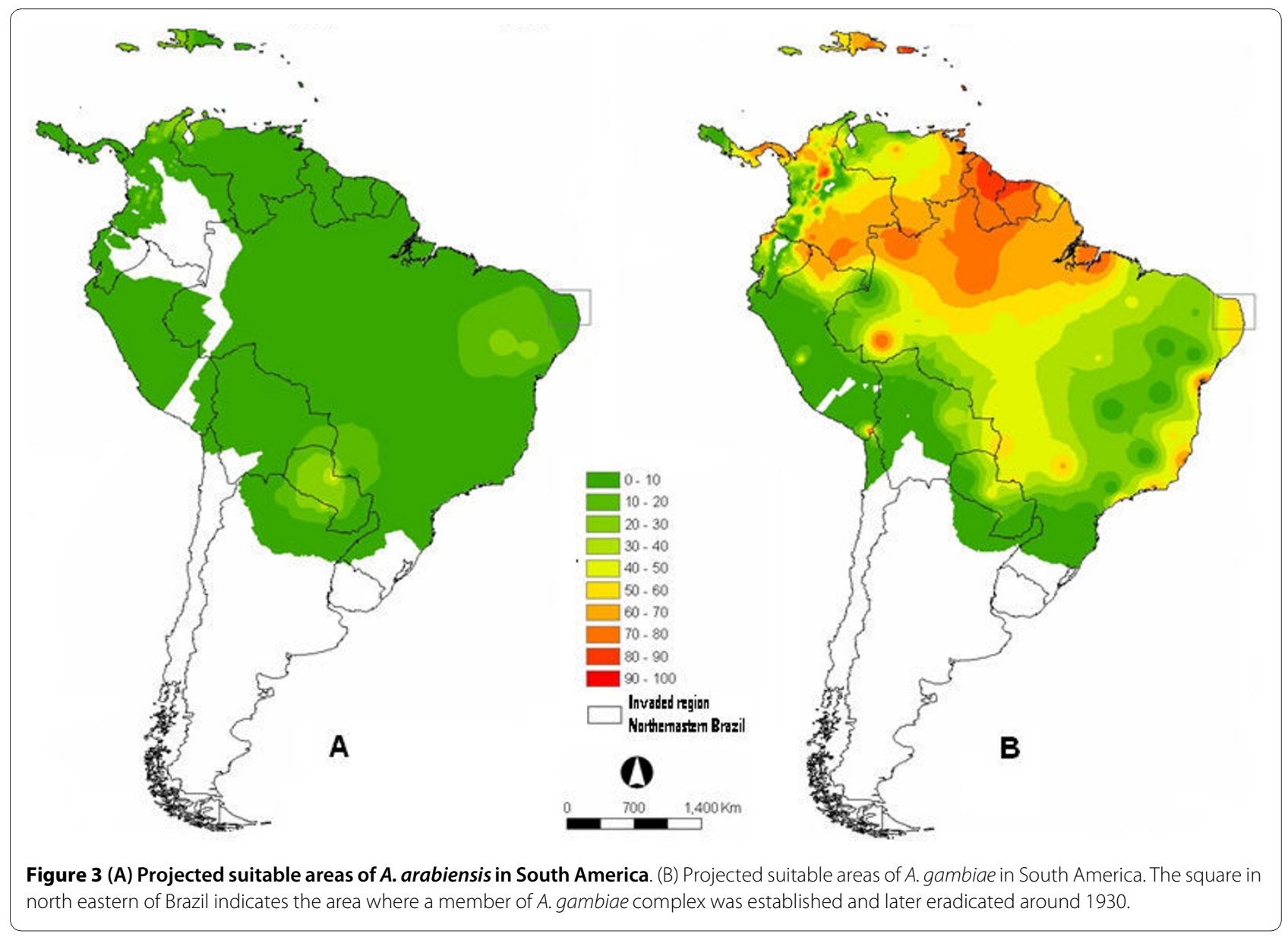


occurred in the past and may continue to occur in the future.

No claim is being made that climate alone is the main determinant factor for Anopheles species existence. However, it is the only factor with available global data that provides an initial estimate of the potential range of Anopheles species. The present study should rather be seen as an illustration of the substantial influence, which the direct effects of climate change may constitute to malaria vectors redistribution in Africa. The results presented here should be interpreted as an indication of the sensitivity of malaria vectors to global climatic changes, particularly temperature rise. More elaborate future risk assessments of climate change on malaria vectors in Africa will ultimately need to include: 1) the global climate-based analysis, 2) local socioeconomic and environmental factors, 3) biotic processes such as competition and predation. These new components will add to comprehension and provide better guidance in taking sustainable and efficient preventive measures for malaria control. Other climate-related disasters such as floods are not to be neglected. This type of event may change the dynamics of malaria vectors by creating conditions that allow proliferation and enhance mosquito-human contact.

It should be emphasized that, the presence of malaria vectors within a region does not automatically translate to the disease. There are many countries in the world where other Anopheles species capable of transmitting malaria lived, however the disease has disappeared. In some countries, such as the USA, this was attributed to population shift from rural to urban areas, improved housing and nutrition, better water management and living standards and greater access to medical service [22]. If by a magic coup, all these conditions are met in the African continent, malaria could as well be reduced. It is important to point out that human activities and behaviour is crucial for malaria transmission. For example, the daily life patterns, the location of homes in relation to mosquitoes breeding sites, the type of materials used to build and the structure of houses, are key determinant factors for transmission of this deadly disease.

\section{Conclusion}

It is essential to recognize here that there are major malaria control efforts underway at present in Africa; and indicators demonstrate remarkable success in malaria control in selected countries in West, East and Southern Africa [23]. However, history has shown that, there is a challenge in maintaining control and, therefore, understanding the role of climate and environment on the potential for future disease risk is highly valuable. These results have increased the understanding of the future geographical distribution of the Anopheles species most responsible for malaria transmission in Africa. They will permit efficient planning of strategies for targeted control or further sampling, detection of competitive interactions, identification of areas in which particular species are potentially involved in malaria transmission, and estimation of risk of introduction to other parts of the world. Informed decisions and actions on these matters is imperative with the changing climate where even traditionally unsuitable areas for Anopheles mosquitoes and malaria have been invaded by the vector and the disease.

\section{Competing interests}

The authors declare that they have no competing interests.

\section{Authors' contributions}

HEZT developed the research proposal, participated in its design and drafted the manuscript. RYMK participated in the implementation and validation and helped to draft the manuscript. PZY provided the funding, coordinated the work and participated in the manuscript write up. All authors read and approved the final manuscript.

\section{Acknowledgements}

This research was carried out under the African Climate Change Fellowship Programme (ACCFP). The ACCFP is supported by a grant from the Climate Change Adaptation in Africa (CCAA), funded jointly by the International Development Research Centre (IDRC) of Canada and the UK's Department of International Development (DFID). The International START Secretariat is the implementing agency in collaboration with the Institute of Resource Assessment (IRA) of the University of Dar es Salaam and the African Academic of Sciences (AAS).

\section{Author Details}

Institute of Resource Assessment, University of Dar Es Salaam, PO Box 35097, Dar es Salaam, Tanzania

Received: 4 December 2009 Accepted: 23 April 2010

Published: 23 April 2010

\section{References}

1. Levine RS, Peterson AT, Benedict MQ: Geographic and ecologic distributions of the Anopheles Gambiea complex predicted using a genetic algorithm. Am J Trop Med Hyg 2004, 70:105-109.

2. Gillies MT, De Meillon B: The Anophelinae of Africa South of the Sahara Publication no. 54. Johannesburg, South Africa. South African Institute of Medical Research; 1968.

3. Gillies MT, Coetzee M: Supplement to the Anophelinae of Africa South of the Sahara Publication no. 55. Johannesburg, South Africa. South African Institute of Medical Research; 1987.

4. Lindsay SW, Parson L, Thomas CJ: Mapping the ranges and relative abundance of the two principal African malaria vectors, Anopheles gambiae sensu stricto and An. arabiensis, using climate data. Proc R Soc Lond B Biol Sci 1998, 265:847-854.

5. Coetzee M, Craig M, Le Sueur D: Distribution of African malaria mosquitoes belonging to the Anopheles gambiae Complex. Parasitol Today 2000, 16:74-77.

6. Harvell CD, Mitchell CE, Ward JR, Altizer S, Dobson AP, Ostfeld RS, Samue $D$ : Climate warming and disease risks for terrestrial and marine biota. Science 2002, 296:2158-2162.

7. Martens P: Climate change impacts on vector-borne diseases in Europe. In Science in Society, Climate Change and Human Health The Royal Society; 1999

8. Lafferty KD: The ecology of climate change and infectious diseases. Ecology 2009, 90:888-900.

9. Sutherst RW, Maywald GF: A computerised system for matching climates in ecology. Agric Ecosyst Environ 1985, 13:281-30.

10. Sutherst RW: Prediction of species geographical ranges. J Biogeogr 2003, 30:805-816.

11. MARA/ARMA [http://www.mara.org.za] 
12. Depinay JM, Mbogo CM, Killen G, Knols B, Beier J, Carlson J, Dushoff J, Billingsley P, Mwambi H, Githure J, Toure AM, McKenzie E: A simulation model of African Anopheles ecology and population dynamics for the analysis of malaria transmission. Malar J 2004, 3:29.

13. Smith DL, McKenzie FE: Statics and dynamics of malaria infection in Anopheles mosquitoes. Malar J 2004, 3:13.

14. Gianotti RL, Bomblies A, Dafalla M, Issa-Arzika I, Duchemin JB, Eltahir EAB: Efficacy of local neem extracts for sustainable malaria vector control in an African village. Malar J 2008, 7:138.

15. Hulme M, Doherty R, Ngara T, New M, Lister D: African climate change: 1900-2100. Climate Research 2001, 17:145-168.

16. Thomas CJ, Davies G, Dunn CE: Mixed picture for the changes in stable malaria distribution with future climate in Africa. Trends Parasitol 2004, 20:216-220

17. Andrewartha $A$, Birch $L C:$ The distribution and abundance of animals University of Chicago Press, Chicago, Illinios, USA; 1954.

18. Pimm S: The balance of nature University of Chicago press, Chicago, Illinios, USA; 1991.

19. Sutherst RW, Maywald GF, Skarratt DB: Predicting insect distributions in a changed climate. In Insects in a changing environment Edited by: Harrington R, Stork NE. Academic Press, London; 1995:59-91.

20. Soper FL, Wilson DB: Anopheles gambiae in Brazil: 1930 to 1940 New York: The Rockefeller Foundation; 1943.

21. Shousha AT: The eradication of Anopheles gambiae from Upper Egypt 1942-1945. Bull World Health Organ 1948, 1:309-353.

22. Gubler DJ, Reiter P, Ebi KL, Yap W, Nasci R, Patz JA: Climate variability and change in the United States: potential impact on vector-and rodentborne diseases. Environ Health Perspective 2001, 109:223-233.

23. WHO: World Malaria Report World Health Organization, Geneva; 2009.

doi: $10.1186 / 1475-2875-9-111$

Cite this article as: Tonnang et al., Predicting and mapping malaria under climate change scenarios: the potential redistribution of malaria vectors in Africa Malaria Journal 2010, 9:111

\section{Submit your next manuscript to BioMed Central} and take full advantage of:

- Convenient online submission

- Thorough peer review

- No space constraints or color figure charges

- Immediate publication on acceptance

- Inclusion in PubMed, CAS, Scopus and Google Scholar

- Research which is freely available for redistribution

Submit your manuscript at www.biomedcentral.com/submit
Ciomed Central 